\title{
Pemberdayaan Masyarakat Dalam Mengendalikan Diabetes Melitus Berbasis Budaya LOKAL
}

\author{
*Mahendro Prasetyo Kusumo', Nur Hidayah', dan Nabila Ardia Pramono ${ }^{3}$ \\ 1,2 Magister Manajemen rumah Sakit, Pascasarjana, Universitas Muhammadiyah Yogyakarta, Jalan Brawijaya, Kasihan, Bantul, \\ Yogyakarta, 55183, Telepon +62 274387656 \\ 3 Pendidikan Dokter, Fakultas Kedoktean dan Ilmu Kesehatan, Universitas Muhammadiyah Yogyakarta, Kasihan, Bantul, Daerah \\ Istimewa Yogyakarta \\ Email: mahendro_prasetyo@umy.ac.id \\ DOI: $10.18196 /$ ppm.39.121
}

\begin{abstract}
Abstrak
Diabetes mellitus (DM) merupakan salah satu penyakit tidak menular (PTM) yang diakibatkan rendahnya dukungan sosial untuk melakukan perilaku sehat. Dukungan soasial tersebut dapat dilakukan melalui edukasi yang disampaikan oleh kader. Tujuan pengabdian ini adalah meningkatkan pengetahuan dan keterampilan kader untuk mendampingi pasien DM di masyarakat dalam mengendalikan glukosa darah. Metode yang digunakan adalah pelatihan kader dan diskusi kelompok. Pelatihan dilaksanakan pada tanggal 19 Februari 2020. Pelatihan diikuti oleh 29 kader yang mewakili setiap dusun di Desa Sidokarto. Kader diberi buku pemantauan kencing manis atau diabetes mellitus (DM) sebagai buku panduan. Materi yang diberikan tentang manajemen DM dan cara komunikasi yang baik. Materi ini disampaikan oleh dokter layanan primer. Hasil evaluasi menunjukkan nilai skor rata-rata adalah 27.71 (15 kader memiliki skor di atas rata-rata dan seluruh kader memiliki lebih dari 75\% jawaban benar). Sebagian besar kader memberikan respons positif terkait materi DM yang diberikan. Keberlanjutan program kader pintar DM dapat dilakukan untuk melaksanakan tugasnya secara konsisten sebagai salah satu upaya pengendalian DM di Desa Sidokarto. Diharapkan program ini bisa diimplementasikan secara maksimal, sehingga bisa menjadi desa percontohan dalam mengendalikan DM. Pelatihan ini mampu meningkatkan pengetahuan kader tentang cara mengendalikan glukosa darah pasien DM.
\end{abstract}

Kata Kunci: diabetes mellitus, pemberdayaan masyarakat, kader

Pendahuluan

World Health Organization (WHO) melaporkan sekitar 150 juta orang di seluruh dunia menderita diabetes mellitus (DM). Diperkirakan jumlah tersebut akan terus meningkat (World Health Organization, 2018), terutama DM tipe 2 (DMT2) (WHO, 2013; WHO, 2016). Salah satu penyebab tingginya jumlah DMT2 adalah rendahnya pengetahuan dan dukungan sosial dalam mengendalikan glukosa darah. Kondisi tersebut menyebabkan jumlah komplikasi akibat DMT2 semakin meningkat.

Meningkatnya jumlah komplikasi pada DMT2 berdampak pada meningkatnya beban ekonomi secara global. Salah satu strategi yang harus dilakukan untuk mengurangi beban ekonomi tersebut adalah dengan gaya hidup sehat secara efektif dan efisien (National Institutes of Health, 2002; Hemmingsen et al., 2017). Aktivitas fisik secara teratur merupakan salah satu gaya hidup sehat yang direkomendasikan WHO dan perkumpulan ahli endokrinologi Indonesia dalam mencegah komplikasi akibat DMT2. Namun, keinginan masyarakat untuk melakukan aktivitas fisik masih rendah. Hal ini kemungkinan disebabkan oleh rendahnya pengetahuan dan dukungan sosial yang diberikan keluarga atau masyarakat sekitar (Ranasinghe et al., 2015). Salah satu bentuk dukungan sosial yang dapat diberikan oleh masyarakat adalah edukasi yang disampaikan oleh kader. Kader yang telah mendapatkan pelatihan atau pendidikan dari tenaga kesehatan dapat memberikan edukasi dan motivasi kepada masyarakat untuk selalu melakukan aktivitas fisik sesuai rekomendasi (Tumbelaka et al., 2018).

Kader kesehatan sebagai promotor kesehatan desa tidak hanya bertugas dalam kegiatan posyandu, tetapi juga dapat mengembangkan kegiatan lainnya yang berkaitan dengan kesehatan. Kader kesehatan merupakan warga asli yang lebih memahami karakteristik dan budaya lokal masyarakat sehingga cara penyampaian informasi akan lebih dapat diterima oleh masyarakat (Shrestha, 2003). 
Berdasarkan wawancara dengan Kepala Desa dan Ketua Kader Sidokarto menyimpulkan bahwa belum ada upaya pengendalian DMT2 secara aktif yang dilakukan oleh kader. Hal tersebut disebabkan belum adanya pelatihan yang efektif tentang DMT2 yang diberikan kepada kader dari puskesmas.

Berdasarkan permasalahan tersebut, perlu dibentuk tim Kader Sidokarto yang fokus membantu mengendalikan DMT2. Kegiatan tersebut perlu dukungan dari pemerintah desa untuk mengadakan pelatihan rutin yang dilakukan setiap tiga bulan sekali. Keberlanjutan program kader DM dapat dilakukan untuk melaksanakan tugasnya secara lebih luas kepada masyarakat sebagai upaya pencegahan penyakit DMT2. Selain itu, program ini dapat meningkatkan upaya kesehatan di Desa Sidokarto. Kegiatan ini bertujuan untuk meningkatkan pengetahuan dan keterampilan kader sehingga dapat mendampingi dan memberikan informasi lebih luas kepada masyarakat serta menggerakkan masyarakat untuk berperilaku hidup sehat.

\section{Metode Pelaksanaan}

Pemberdayaan "kader pintar" dilakukan di Desa Sidokarto, Godean, Sleman. Pemberdayaan dilaksanakan menggunakan metode diskusi kelompok. Program tersebut menekankan pada peran aktif ibu-ibu kader terlatih untuk membantu mendampingi masyarakat di sekitarnya dalam mencegah komplikasi akibat DMT2. Melalui program tersebut, Desa Sidokarto dapat dijadikan sebagai desa percontohan yang menerapkan program kader pintar menuju desa sehat. Program tersebut diimplementasikan melalui pelatihan kader yang dilaksanakan pada tanggal 19 Februari 2020 pada 29 kader yang mewakili setiap dusun di Desa Sidokarto. Program diujicobakan di Desa Sidokarto dikarenakan kesehatan desa tersebut telah berhasil memberdayakan kader dalam memantau perkembangan kesehatan balita. Materi yang disampaikan dalam pelatihan sebagai berikut.

Tabel 1. Materi Pelatihan

\begin{tabular}{cl}
\hline No & \multicolumn{1}{c}{ Materi } \\
\hline 1 & Risiko Diabetes Mellitus \\
2 & Tanda dan Gejala Diabetes Mellitus \\
3 & Cara Pencegahan Diabetes Mellitus \\
4 & Manajemen penyakit Diabetes Mellitus \\
\hline
\end{tabular}

Kader juga dilatih cara aktivitas fisik yang mudah dan praktis dilakukan serta komunikasi efektif. Materi ini disampaikan oleh dokter layanan primer. Kader diberikan buku pemantauan kencing manis atau diabetes mellitus (DM) sebagai buku panduan. Buku tersebut juga digunakan masyarakat yang terdiagnosis DMT2 sebagai panduan untuk melakukan perilaku hidup sehat. Buku tersebut berisi tentang ringkasan penyakit DM, program aktivitas fisik dan kontrol pola makan bagi pasien DMT2.

Metode yang digunakan untuk menyampaikan materi adalah dengan tatap muka. Program kemudian dilakukan evaluasi melalui pengisian kuesioner yang berisi pertanyaan terkait risiko diabetes mellitus, tanda dan gejala diabetes mellitus, cara pencegahan diabetes mellitus, dan manejemen diabetes mellitus. Kemudian hasil pengisian kuesioner dianalisis untuk dievaluasi hasilnya.

\section{Hasil dan Pembahasan}

Implementasi sukarelawan kesehatan (community health voluunteer) dilakukan untuk menyediakan layanan kesehatan bagi komunitas di beberapa negara salah satunya Indonesia yang sering disebut dengan kader kesehatan. Community Health Volunteer (CHV) memiliki 
peran penting dalam meningkatkan layanan sistem kesehatan dan mendekatkan pelayanan kesehatan pada masyarakat (McCollum et al., 2016). Community Health Volunteer berfokus pada layanan preventif dan promotif dan dalam pelayanannya dibutuhkan pengetahuan serta keterampilan (Shrestha, 2003).

Program pemberdayaan "kader pintar" dilakukan dengan menekankan pada peran aktif ibu-ibu kader terlatih untuk membantu mendampingi masyarakat di sekitarnya dalam mencegah komplikasi akibat DMT2. Melalui program ini, Desa Sidokarto dapat menjadi desa percontohan yang menerapkan program kader pintar menuju desa sehat. Pelatihan di ikuti oleh 29 kader yang mewakili setiap dusun di Desa Sidokarto. Setelah dilakukan pelatihan, kader dilakukan evaluasi dengan memberikan kuesioner yang terdiri atas 15 pertanyaan.

\begin{tabular}{lccc} 
Tabel 2. Hasil Evaluasi & Pengetahuan Kader Setelah Dilakukan & Pelatihan \\
\hline $\begin{array}{l}\text { Nilai Evaluasi Pengetahuan Kader } \\
\text { tentang DM }\end{array}$ & Nilai & Nilai & Rata-rata \\
& Minimum & Maksimum & \\
\cline { 2 - 4 } & 23 & 30 & 26.71
\end{tabular}

Berdasarkan hasil evaluasi, diketahui rata-rata skor dari 28 kader yang mengisi kuesioner evaluasi adalah 26.71. Berdasarkan hasil evaluasi tersebut juga diketahui bahwa 15 kader memiliki skor di atas rata-rata dan 13 kader memiliki skor di bawah rata-rata, tetapi seluruh kader (100\%) memiliki lebih dari $75 \%$ skor jawaban benar. Hasil tersebut menunjukkan bahwa pemberdayaan kader yang dilakukan dapat memberikan wawasan kepada kader tentang diabetes mellitus. Hasil ini sejalan dengan penelitian sebelumnya yang menjelaskan bahwa pelatihan tentang PTM dapat meningkatkan pengetahuan kader secara signifikan $(\mathrm{p}<0.01)$ (Rahayu et al., 2020).

Pada saat pelatihan sebagian besar kader memberikan respons positif dengan cara mendengarkan dan memberikan penegasan tentang materi DM yang mereka pahami. Sebagian besar kader juga mengajukan pertanyaan seputar perilaku hidup sehat, termasuk cara mengendalikan stres. Motivasi dapat dilakukan melalui peningkatan hubungan antarkader, saling berbagi pengalaman dengan anggota kader, serta membangun hubungan antara kader dan komunitas (Singh et al., 2016).

Melalui program tersebut diharapkan dapat meningkatkan motivasi kader untuk selalu mendampingi masyarakat dengan DMT2. Selama pelatihan, komunikasi efektif dua arah sangat diperlukan untuk meningkatkan partisipasi dan peran aktif kader. Berdasarkan penelitian sebelumnya dijelaskan bahwa metode pelatihan dan durasi sangat penting diperhatikan dalam pemberian pelatihan CHV agar efektif (Tumbelaka et al., 2018). Kader kesehatan dilatih cara berkomunikasi yang baik sehingga kader dapat dengan mudah memberikan edukasi kepada masyarakat sekitar. Kader kesehatan sebagai penduduk lokal mampu untuk melakukan kegiatan pemantauan kesehatan serta melakukan promosi kesehatan di daerahnya (Gau et al., 2013). Peningkatan kinerja kader memiliki dampak yang baik bagi perubahan perilaku masyarakat (Ballard \& Montgomery, 2017). Faktor yang memengaruhi kinerja kader kesehatan di antaranya adalah adanya intesif, adanya pengawasan, serta keterlibatan masyarakat dan koordinasi yang kuat antara kader kesehatan dengan profesional kesehatan (Kok et al., 2015). Selain itu, perlu pendekatan multi-level, salah satunya, yaitu dukungan dari pemangku kebijakan dalam meningkatkan motivasi CHV(Strachan et al., 2012). Terdapat beberapa permasalahan kader di antaranya kurangnya orientasi program, kurangnya edukasi, kurangnya keterampilan komunikasi, kurangnya kepercayaan diri dan dukungan terhadap peran kader (Gau et al., 2013). Pelatihan sukarelawan kesehatan dapat meningkatkan pengetahuan dan keterampilan terkait promosi kesehatan serta meningkatkan motivasi dan kepercayaan diri (Tumbelaka et al., 2018). Selain itu, pelatihan kader juga meningkatkan kemampuan komunikasi bagi kader dan meningkatkan kepuasan terhadap peran sebagai kader (Nasir et al., 2013; Kawasaki et al., 
2015). Keberlanjutan pelatihan kader kesehatan mampu meningkatkan peran kader dalam melakukan tugasnya (Kok et al., 2015).

\section{Simpulan}

Pemberdayaan kader yang dilakukan mampu meningkatkan pengetahuan dan keterampilan kader tentang pengendalian glukosa darah pasien DM. Selain itu, pelatihan yang disampaikan dokter kepada kader mampu menghasilkan "kader pintar" yang dapat berperan sebagai pendamping masyarakat Desa Sidokarto dalam mengendalikan DM.

\section{Ucapan Terima Kasih}

Terima kasih kepada lembaga penelitian dan pengabdian dan pemberdayaan masyarakat (LP3M) Universitas Muhammadiyah Yogyakarta atas dukungan dana dalam pengabdian masyarakat ini. Terima kasih juga kepada Pemerintah Desa Sidokarto, Godean, Sleman yang telah bekerja sama dalam pemberdayaan masyarakat di Desa Sidokarto.

\section{Daftar Pustaka}

Ballard, M., \& Montgomery, P. (2017). Systematic Review of Interventions for Improving the Performance of Community Health Workers in Low-Income and Middle-Income Countries. BMJ Open, 7(10). https://doi.org/10.1136/bmjopen-2016-014216.

Gau, Y. M., Buettner, P., Usher, K., \& Stewart, L. (2013). Burden Experienced by Community Health Volunteers in TAIWAN: A survey. BMC Public Health, 13(1), 1. https://doi.org/10.1186/1471-2458-13-491.

Hemmingsen, B., Gimenez-Perez, G., Mauricio, D., Roqué i Figuls, M., Metzendorf, M.-I., \& Richter, B. (2017). Diet, Physical Activity or Both for Prevention or Delay of Type 2 Diabetes Mellitus and Its Associated Complications in People at Increased Risk of Developing Type 2 Diabetes Mellitus. Cochrane Database of Systematic Reviews. https://doi.org/10.1002/14651858.CD003054.pub4.

Kawasaki, R., Sadamori, T., Ferreira de Almeida, T., Akiyoshi, M., Nishihara, M., Yoshimura, T., \& Ohnishi, M. (2015). Reactions of Community Members Regarding Community Health Workers' Activities as A Measure of the Impact of A Training Program in Amazonas, Brazil. Journal of Rural Medicine, 10(1), 7-19. https://doi.org/10.2185/jrm.2890.

Kok, M. C., Dieleman, M., Taegtmeyer, M., Broerse, J. E. W., Kane, S. S., Ormel, H., ... De Koning, K. A. M. (2015). Which intervention design factors influence performance of community health workers in low- and middle-income countries? A systematic review. Health Policy and Planning, 30(9), 1207-1227. https://doi.org/10.1093/heapol/czu126.

McCollum, R., Gomez, W., Theobald, S., \& Taegtmeyer, M. (2016). How Equitable are Community Health Worker Programmes and Which Programme Features Influence Equity of Community Health Worker Services? A Systematic Review. BMC Public Health, 16(1), 1-16. https://doi.org/10.1186/s12889-016-3043-8.

Nasir, S., Magdalena, A., Limato, R., Tumbelaka, P., Syafruddin, D., \& Ahmed, R. (2013). Impact of Health Promotion Trainings of Community Health Providers on Community 
Maternal Health Services in Cianjur, Indonesia.

National Institutes of Health. (2002). The Diabetes Prevention Program (DPP): Description of Lifestyle Intervention. Diabetes Care, 25(12), 2165-2171. https://doi.org/10.2337/diacare.25.12.2165.

Rahayu, E., Kurniawan, D. W., \& Shodiq, D. (2020). Effectiveness of Training on Improving Knowledge of Non Communicable Diseases Cadres Rempoah Village Baturraden District Banyumas Regency. Journal of Community Heath Development, 1(1), 27-32.

Ranasinghe, P., Pigera, A. S. A. D., Ishara, M. H., Jayasekara, L. M. D. T., Jayawardena, R., \& Katulanda, P. (2015). Knowledge and Perceptions about Diet and Physical Activity Among Sri Lankan Adults with Diabetes Mellitus: A Qualitative Study Health Behavior, Health Promotion and Society. BMC Public Health, 15(1), 1-10. https://doi.org/10.1186/s12889015-2518-3.

Shrestha, S. (2003). A Conceptual Model for Emporwerment of the Female Community Health Volunteers in Nepal. Education for Health, 16(3), 318-327.

Singh, D., Cumming, R., Mohajer, N., \& Negin, J. (2016). Motivation of Community Health Volunteers in Rural Uganda: the Interconnectedness of Knowledge, Relationship and Action. Public Health, 136, 166-171. https://doi.org/10.1016/j.puhe.2016.01.010.

Strachan, D. L., Källander, K., Ten Asbroek, A. H. A., Kirkwood, B., Meek, S. R., Benton, L., ... Hill, Z. (2012). Interventions to Improve Motivation and Retention of Community Health Workers Delivering Integrated Community Case Management (iCCM): Stakeholder Perceptions and Priorities. American Journal of Tropical Medicine and Hygiene, 87(SUPPL.5), 111-119. https://doi.org/10.4269/ajtmh.2012.12-0030.

Tumbelaka, P., Limato, R., Nasir, S., Syafruddin, D., Ormel, H., \& Ahmed, R. (2018). Analysis of Indonesia's community Health Volunteers (Kader) as Maternal Health Promoters in the Community Integrated Health Service (Posyandu) Following Health Promotion Training. International Journal of Community Medicine And Public Health, 5(3), 856. https://doi.org/10.18203/2394-6040.ijcmph20180462.

WHO. (2013). Action Plan for the Global Strategy for the Prevention and Control of Noncommunicable Diseases.

WHO. (2016). Global Report on Diabetes. Isbn, 978, 6-86. Retrieved from http://www.who.int/about/licensing/.

World Health Organization. (2018). NCDs | Noncommunicable diseases and Their Risk Factors. Who, pp. 1-4. Retrieved from https://www.who.int/ncds/en/\%0Ahttp://www.who.int/ncds/en/. 